\author{
Nuno S. Graça' \\ Luís S. Pais ${ }^{2}$ \\ Alírio E. Rodrigues ${ }^{1}$ \\ 'Laboratory of Separation and \\ Reaction Engineering (LSRE), \\ Associate Laboratory LSRE/ \\ LCM, Department of Chemical \\ Engineering, Faculty of \\ Engineering, University of \\ Porto, Porto, Portugal. \\ ${ }^{2}$ Laboratory of Separation and \\ Reaction Engineering (LSRE), \\ Associate Laboratory LSRE/ \\ LCM, School of Technology \\ and Management, Polytechnic \\ Institute of Bragança, Bragança, \\ Portugal.
}

\section{Separation of Ternary Mixtures by Pseudo- Simulated Moving-Bed Chromatography: Separation Region Analysis}

\begin{abstract}
The application of the pseudo-simulated moving bed process, known as JO process of Japan Organo Co., to the separation of ternary mixtures was studied. In order to perform a desired separation, the choice of the different operation parameters such as the duration of each step and its respective flow rates requires the use of a methodology that could provide the best process performance. This issue is addressed by proposing an innovative method to determine the JO operation region, which establishes the operation limits of the process. In addition, a methodology is presented to determine the separation region where a minimum purity requirement is guaranteed. This methodology was applied to a ternary mixture considering linear adsorption isotherms. It was possible to construct a separation region for minimum purity of $99.9 \%$ in all the outlet streams and identify the best operation point in terms of the process performance.
\end{abstract}

Keywords: Preparative chromatography, Pseudo-simulated moving bed, Separation region analysis, Simulated moving bed, Ternary mixtures

Received: March 17, 2015; revised: June 01, 2015; accepted: July 14, 2015

DOI: $10.1002 /$ ceat.201500157

\section{Introduction}

The concept of simulated moving bed (SMB) was patented in 1961 by Broughton and Gerhold from UOP [1]. Since then, several applications were implemented in different areas, such as the Parex process for the separation of $p$-xylene from a $\mathrm{C}_{8}$ mixture, the Sarex process for the production of high-fructose corn syrup and sucrose from molasses [2], chiral separations [3-5] and bio-purifications $[2,6,7]$. In the last decades, several new SMB-based processes were proposed such as Powerfeed $[8,9]$, Modicon [10], Varicol [11], FF-SMB [12,13], Outlet Stream Swing [13], and BackFill-SMB [14]; also the optimization of the SMB operation conditions has been an important field of study $[15,16]$. More recently, the SMB concept was applied to reactive systems for the production of green solvents and fuel additives [17-19].

The simulation of a continuous contact between the solid and the liquid phases, provided by the periodical switch of inlet and outlet SMB streams, enhances the mass-transfer driving force, leading to a significant reduction in the mobile and stationary phase consumption when compared with the fixed-

Correspondence: Dr. Nuno S. Graça (nunopsg@fe.up.pt), Laboratory of Separation and Reaction Engineering (LSRE), Associate Laboratory LSRE/LCM, Department of Chemical Engineering, Faculty of Engineering, University of Porto, Rua Dr. Roberto Frias, 4200-465 Porto, Portugal. bed chromatography [20]. However, the SMB process is limited to the separation of binary or pseudo-binary mixtures or to the recovery of one component from a multicomponent mixture.

Several configurations have been proposed in order to extend the SMB process to the separation of multicomponent mixtures, such as the separation of ternary mixtures by two or more SMB in series $[21,22]$ and the use of a five-zone SMB system for the multicomponent separation of some sugars [23] and chiral molecules [24]. More recently, Jermann et al. extended the concept of intermittent SMB (I-SMB) [25] to the separation of ternary mixtures [26].

In 1990, a new derivation of the SMB concept, denominated JO SMB process, was patented [27] and applied by the Japan Organo company in the separation of complex multicomponent mixtures such as the separation of beet molasses into raffinose, sucrose, glucose, and betaine [28]. The JO concept combines the features of both fixed-bed chromatography and SMB process in a two-step continuous process [29].

The JO process applied to ternary mixtures is a cyclic process involving two discrete steps. In the first step, the system works as a series of chromatographic columns with the feed and the eluent as inlet streams, and the component with the intermediate affinity with the solid phase being collected. In the second step, the system works as an SMB unit without feed stream, and the more and the less retained components are recovered at the extract and raffinate outlet streams, respectively. It is important to point out that the implementation of the JO process on any SMB system is a relatively easy task, which can be made without any major hardware modification [30]. 
In this work, a mathematical model of the JO process for the separation of a ternary mixture, in which step 1 is a series of fixed-bed chromatographic columns and step 2 considers a true moving bed (TMB) operation with no feed, is used [31]. A new methodology for the determination of operational limits and for the construction of the separation regions is presented. The influence of mass transfer resistance in the separation regions is also analyzed. Relatively to other methodologies described in previous works [31-33], this new methodology allows the mapping of the operating limits in terms of process performance, i.e., for a given separation problem and system configuration, the range of process operation conditions becomes welldefined. Moreover, the knowledge of the process operation limits is decisive in the further optimization of the process.

\section{Mathematical Model}

The cyclic operation of the JO process involves the following two steps:

1) In the first step, the feed and the eluent streams enter into the system and the intermediate component is collected.

2) In the second step, the system works as a true moving bed with no feed. The only inlet flow is the eluent, the most adsorbed component is collected in the extract, and the less adsorbed component is collected in the raffinate.

The mathematical model was defined based on the dimensionless variables for space and time $x=\frac{z}{L_{j}}$ and $\theta=\frac{t}{\tau_{2}}$, respectively, with $\tau_{2}=\frac{L_{j}}{u_{\mathrm{s}}}=n_{\mathrm{Sj}} t^{*}$ and $u_{\mathrm{s}}=\frac{L_{C}}{t^{*}}$ where $t^{\star 1)}$ is the SMB switching time interval and $u_{\mathrm{s}}$ is the interstitial solid velocity in the equivalent $\mathrm{TMB}, n_{\mathrm{S} j}$ is the number of columns in section $j$ of the SMB unit, $L_{j}$ is the length of an SMB section, and $L_{\mathrm{c}}$ is the length of one SMB column.

\subsection{Mathematical Model for Step 1}

The mathematical model for this step considers a series of chromatographic columns arranged in four sections. Section 2 is disconnected from section 3 , and the intermediate stream is collected at the end of section 2. Besides this output flow, $Q_{\mathrm{I}}$, there are two input flows: the eluent, $Q_{\mathrm{E}, \mathrm{S} 1}$, at the entrance of section 1 , and the feed, $Q_{\mathrm{F}}$, at the entrance of section 3 (Fig. 1).

The model equations $[31,32]$ are based on the assumption of axial dispersion flow for the fluid phase and a linear driving force model for intraparticle mass transfer:

Mass balance in the bulk fluid phase:

$\frac{\partial C_{i j}}{\partial \theta}=\gamma_{j}\left(\frac{1}{P e_{j}} \frac{\partial^{2} C_{i j}}{\partial x^{2}}-\frac{\partial C_{i j}}{\partial x}\right)-\frac{(1-\varepsilon)}{\varepsilon} \alpha_{j}\left(q_{i j}{ }^{*}-q_{i j}\right)$

where $C_{i j}$ and $q_{i j}$ are the fluid and average adsorbed phase concentrations of component $i$ in section $j, q_{i j}{ }^{*}$ is the adsorbed phase concentration at the particle surface in equilibrium with
STEP 1

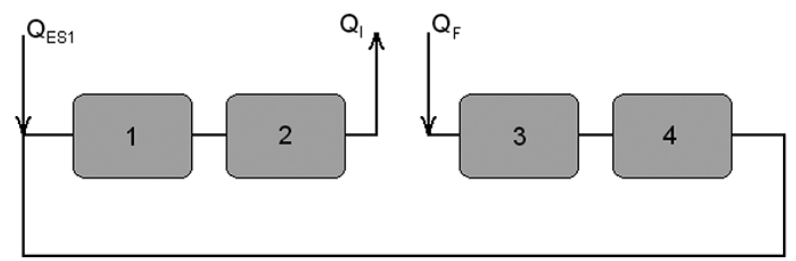

STEP 2

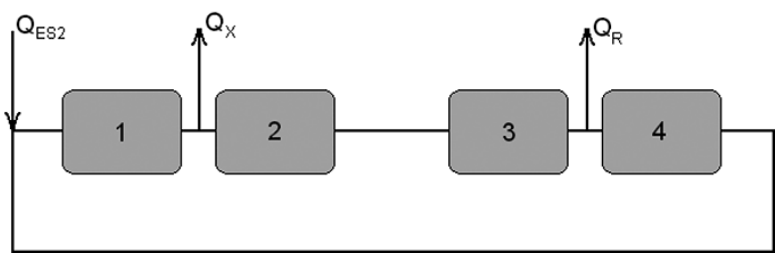

Figure 1. Schematic representation of the JO process. Step 1: series of fixed-bed columns with feed and collection of the intermediate product (B); step 2: SMB operation with no feed and collection of raffinate (product $A$ ) and extract (product $C$ ).

$C_{i j}, \varepsilon$ is the bed porosity, $\gamma_{j}=\frac{v_{j}}{u_{\mathrm{s}}}$ is the ratio of fluid and solid interstitial velocities, $\alpha_{j}=\tau_{2} k_{\mathrm{p}}$ is the number of intraparticle mass transfer units with $k_{\mathrm{p}}$ being the intraparticle mass transfer coefficient, and $P e_{j}=\frac{v_{j} L_{j}}{D_{L_{j}}}$ is the Péclet number with $D_{L_{j}}$ as the axial dispersion coefficient.

Mass balance in the particle:

$\frac{\partial q_{i j}}{\partial \theta}=\alpha_{j}\left(q_{i j}^{*}-q_{i j}\right)$

The initial conditions for step 1 are:

$q_{i j}(\theta=0$, step 1, cycle 1$)=$

$C_{i j}(\theta=0$, step 1, cycle 1$)=0$

$C_{i j}(\theta=0$, step 1, cycle $k)=$

$C_{i j}\left(\theta=\theta_{\mathrm{S} 2}\right.$, step 2 , cycle $\left.k-1\right)$

$q_{i j}(\theta=0$, step 1, cycle $k)=$

$q_{i j}\left(\theta=\theta_{\mathrm{S} 2}, \quad\right.$ step 2, cycle $\left.k-1\right)$

and the two boundary conditions for each section $j$ are:

$x=0: \quad C_{i j, 0}=C_{i j}-\frac{1}{P e_{j}} \frac{\mathrm{d} C_{i j}}{\mathrm{~d} x}$

where

Feed node : $\quad C_{i 3,0}=C_{i}^{\mathrm{F}}$

Eluent node : $\quad C_{i 1,0}=\frac{Q_{4}}{Q_{1}} C_{i 4,1}$

1) List of symbols at the end of the paper. 
Raffinate and extract nodes : $\quad C_{i j, 1}=C_{i j+1,0}$

and

$x=1:\left.\frac{\mathrm{d} C_{i j}}{\mathrm{~d} x}\right|_{x=1}=0$

\subsection{Mathematical Model for Step 2}

In this step, the equivalent TMB model was used. The system presents two outlet flows, the extract, $Q_{\mathrm{X}}$, and the raffinate, $Q_{\mathrm{R}}$, and one inlet flow, the eluent $Q_{\mathrm{E}, \mathrm{S} 2}$ (Fig. 1). There is no feed flow in this step; therefore, the flow rate in section 2 and 3 is the same.

In this TMB model, the equation for the bulk liquid phase is the same of Eq. (1). The particle phase equation has to take into account the movement of the solid phase and is given by:

$\frac{\partial q_{i j}}{\partial \theta}=\frac{\partial q_{i j}}{\partial x}+\alpha_{j}\left(q_{i j}^{*}-q_{i j}\right)$

The initial and boundary conditions for this step are:

$C_{i j}(\theta=0$, step 2, cycle 1$)=$

$C_{i j}(\theta=0$, step 1, cycle 1$)$

$q_{i j}(\theta=0$, step 2, cycle 1$)=$

$q_{i j}(\theta=0$, step 1 , cycle 1$)$

$C_{i j}\left(\theta=\theta_{\mathrm{S} 1}\right.$, step 2, cycle $\left.k\right)=$

$C_{i j}\left(\theta=\theta_{\mathrm{S} 1}\right.$, step 1 , cycle $\left.k\right)$

$q_{i j}\left(\theta=\theta_{\mathrm{s} 1}\right.$, step 2, cycle $\left.k\right)=$

$q_{i j}\left(\theta=\theta_{\text {S1 }}\right.$, step 1 , cycle $\left.k\right)$

The boundary conditions are given by Eqs. (6) and (10). The eluent node is defined by Eq. (8) and since there is no feed or any other inlet stream, the remaining nodes are defined by Eq. (9).

\subsection{Numerical Method}

The mathematical model was solved with the general Process Modeling System (gPROMS, version 3.1.5, www.psenterprise. com). The axial coordinate was discretized using the thirdorder orthogonal collocation in finite elements (OCFEM). The system of ordinary differential equations (ODEs), resulting from the axial discretization, was integrated over the time by the DASOLV integrator implemented in gPROMS. For axial discretization 50 finite elements were employed. All simulations had a fixed tolerance equal to $10^{-7}$.

\section{Determination of the Operating Conditions}

After the establishment of the mathematical model it is necessary to determine the operating conditions for both step 1 and step 2 in order to obtain the desired separation and the best process performance.

The case study used in the present work is the same as that of Mata and Rodrigues [31], the adsorption equilibrium isotherms are considered linear. Adsorption parameters and feed concentration are presented in Tab. 1 .

Table 1. Adsorption parameters and concentrations for the ternary mixture.

\begin{tabular}{lll}
\hline Component & $\begin{array}{l}\text { Linear isotherm } \\
\text { parameter }\left(K_{\mathrm{i}}\right)\end{array}$ & $C_{\mathrm{F}}\left[\mathrm{g} \mathrm{L}^{-1}\right]$ \\
\hline A (less retained) & 0.19 & 100 \\
B (intermediate) & 0.39 & 100 \\
C (more retained) & 0.65 & 100 \\
\hline
\end{tabular}

This kind of linear adsorption isotherms appears in some practical separations such as the separation of oligosaccharides $[34,35]$.

The system consists of twelve chromatographic columns with characteristics presented in Tab. 2. It is assumed that the mass transfer coefficient $k_{\mathrm{p}}$ is $0.5 \mathrm{~s}^{-1}$ and the Péclet number $P e$ is 2000 .

Table 2. Characteristics of the SMB columns.

\begin{tabular}{ll} 
Number of columns (total) & 12 \\
Column length $[\mathrm{cm}]$ & 120 \\
Column diameter $[\mathrm{cm}]$ & 10.84 \\
Column volume [L] & 11.1 \\
Number of columns per section & 3 \\
Bed porosity $\varepsilon$ & 0.4 \\
\hline
\end{tabular}

\subsection{Operation Conditions for Step 1}

The flow rate in section 1 during step $1, Q_{1, S 1}$, is an important operation condition because it sets the maximum pressure drop allowed in the system. By setting the value of $Q_{1, S 1}$ it is possible to determine the duration of step $1, t_{\mathrm{S} 1}$, according to the following expression:

$t_{\mathrm{S} 1}=p_{\mathrm{QS} 1} \varepsilon \frac{L_{\mathrm{C}} A_{\mathrm{C}}}{Q_{1, \mathrm{~S} 1}} \phi_{\mathrm{B}} \quad\left(0<p_{\mathrm{QS} 1}<n_{\mathrm{S} 2}\right)$

where

$\phi_{\mathrm{B}}=1+\frac{1-\varepsilon}{\varepsilon} K_{\mathrm{B}}$ 
The parameter $p_{\mathrm{QS} 1}$ represents the distance traveled by the intermediate component inside section 2 during step 1, normalized by the length of one column, $L_{\mathrm{C}}$. The parameter $p_{\mathrm{QS} 1}$ was set as 2 . This value was chosen since, in almost all cases during step 2, the intermediate component will be placed within the last two columns of section 2, counting in liquid flow direction; therefore, to ensure its recovery, the intermediate component has to travel at least two columns.

The duration of step $1, t_{\mathrm{S} 1}$, can be also determined based on the retention time of component $\mathrm{B}$ according to Eq. (18). The complete derivation of Eq. (18) is presented in Appendix A.

$t_{S 1}=\bar{t}_{\mathrm{B}}\left[1-2 \sqrt{\frac{2}{P e}+\frac{2}{k_{\mathrm{p}} \bar{t}_{\mathrm{B}}}\left(\frac{\phi_{\mathrm{B}}-1}{\phi_{\mathrm{B}}}\right)}\right]$

By determining the value of $t_{\mathrm{S} 1}$ with Eq. (16), $\bar{t}_{B}$ is obtained from Eq. (18) which allows the calculation of the feed flow rate during step 1 according to the following equation:

$Q_{\mathrm{F}}=p_{t \mathrm{~S} 1} \frac{\varepsilon A_{\mathrm{C}} L_{\mathrm{c}}}{\bar{t}_{\mathrm{B}}} \phi_{\mathrm{B}} \quad\left(0<p_{t \mathrm{~S} 1}<n_{\mathrm{S} 3}\right)$

The value of the parameter $p_{t s 1}$ used was 1 , which means that the intermediate component travels the distance of one column inside section 3 from the feed point.

In the JO operation, the maximum flow rate occurs in section 1 . The maximum flow rate results from the maximum pressure drop allowable in the system and from equipment limitations such as pump capacity. In this work, the maximum flow rate was set as $Q_{1, \mathrm{~S} 1}=Q_{\max }=772.9 \mathrm{~mL} \mathrm{~min}^{-1}$.

The duration of step 1, the feed, and eluent flow rates can be calculated by Eqs. (16)-(19): $t_{\mathrm{S} 1}=18.17 \mathrm{~min}, Q_{\mathrm{F}}=350 \mathrm{~mL}$ $\mathrm{min}^{-1}$, and $Q_{\mathrm{E}, \mathrm{S} 1}=422.9 \mathrm{~mL} \mathrm{~min}^{-1}$.

\subsection{Operating Conditions for Step 2}

In the development of the proposed method an auxiliary parameter, $p_{i}$, is used which represents the distance traveled by the component $i$ relatively to the feed point during step 2 (Fig. 2).

The propagation of the concentration fronts of each component during the first cycle of the JO process is illustrated in Fig. 3. During the first step all the components that enter through the feed port are carried by the liquid phase. During the second step only the less adsorbed component is carried by the liquid phase while the most adsorbed and intermediate components are carried by the solid phase in the opposite direction.

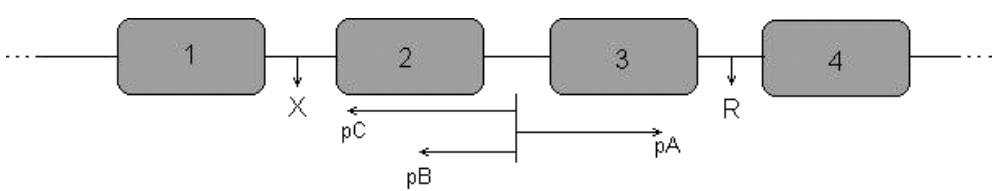

Figure 2. Schematic representation of parameter $p_{\mathrm{i}}$ during step 2 of the JO process.

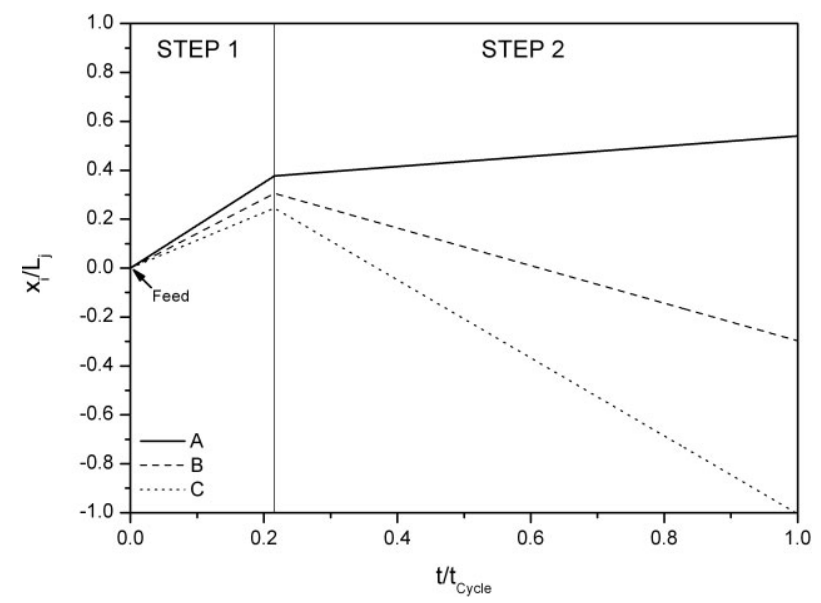

Figure 3. Position of concentration fronts during the first cycle of JO operation. Step 1: $t_{\mathrm{S} 1}=18.17 \mathrm{~min}, Q_{\mathrm{F}}=350.0 \mathrm{~mL} \mathrm{~min}^{-1}$, $Q_{\mathrm{E}, \mathrm{S} 1}=422.9 \mathrm{~mL} \mathrm{~min}^{-1}$. Step 2: $t_{\mathrm{S} 2}=66 \mathrm{~min}, t^{*}=5.68 \mathrm{~min}$,

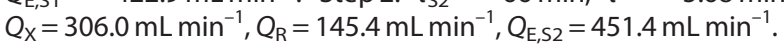

The flow rate in sections 2 and $3, Q_{2 / 3, \mathrm{~S} 2}$, is given by:

$Q_{2 / 3, \mathrm{~S} 2}=\left[\frac{\phi_{\mathrm{C}} K_{\mathrm{B}}\left(x_{\mathrm{C} 3, \mathrm{~S} 1}+p_{\mathrm{C}} L_{\mathrm{c}}\right)-\phi_{\mathrm{B}} K_{\mathrm{C}}\left(x_{\mathrm{B} 3, \mathrm{~S} 1}+p_{\mathrm{B}} L_{\mathrm{c}}\right)}{\phi_{\mathrm{C}}\left(x_{\mathrm{C} 3, \mathrm{~S} 1}+p_{\mathrm{C}} L_{\mathrm{c}}\right)-\phi_{\mathrm{B}}\left(x_{\mathrm{B} 3, \mathrm{~S} 1}+p_{\mathrm{B}} L_{\mathrm{c}}\right)}\right] Q_{\mathrm{s}}$

and the duration of step $2, t_{\mathrm{S} 1}$, is defined by:

$t_{\mathrm{S} 2}=\frac{\varepsilon A_{\mathrm{C}}}{Q_{\mathrm{S}}\left(K_{\mathrm{C}}-K_{\mathrm{B}}\right)}\left[\phi_{\mathrm{C}}\left(x_{\mathrm{C} 3, \mathrm{~S} 1}+p_{\mathrm{C}} L_{\mathrm{c}}\right)-\phi_{\mathrm{B}}\left(x_{\mathrm{B} 3, \mathrm{~S} 1}+p_{\mathrm{B}} L_{\mathrm{c}}\right)\right]$

where $x_{i j, \mathrm{~S} 1}$ is the distance traveled by component $i$ inside section $j$ during step 1 , and is given by:

$x_{i j, S 1}=\frac{t_{S 1} Q_{j, S 1}}{\varepsilon A_{c} \phi_{i}}$

and,

$\phi_{i}=1+\frac{1-\varepsilon}{\varepsilon} K_{i}$

In order to guarantee that all the components are moving in the correct direction (Fig. 2), the following relation should be satisfied:

$$
\begin{aligned}
p_{\mathrm{B}} & \leq \frac{\phi_{\mathrm{C}}}{\phi_{\mathrm{B}}}\left(\frac{x_{\mathrm{C}, 3, \mathrm{~S} 1}}{L_{\mathrm{C}}}+p_{\mathrm{C}}\right)\left(\frac{K_{\mathrm{B}}-K_{\mathrm{A}}}{K_{\mathrm{C}}-K_{\mathrm{A}}}\right) \\
& -\frac{x_{\mathrm{C}, 3, \mathrm{~S} 1}}{L_{\mathrm{C}}}
\end{aligned}
$$

Therefore, the determination of the operation conditions of step 2 depends on the choice of a pair of the parameters $p_{\mathrm{B}}$ and $p_{\mathrm{C}}$ that satisfy Eq. (24). The complete derivations of Eqs. (20), (21), and (24) are presented in Appendix A. 
It is also necessary to guarantee that during step 2 of the JO operation the less retained component $(\mathrm{A})$ is not recycled to section 1 with the liquid phase and the more retained component $(\mathrm{C})$ is not carried with the solid phase to section 4. Mathematically, these constraints can be expressed by:

$Q_{1, \mathrm{~S} 2}=\beta Q_{\mathrm{S}} K_{\mathrm{C}}-\frac{t_{\mathrm{S} 1}}{t_{\mathrm{S} 2}}\left(Q_{\mathrm{F}}+Q_{\mathrm{E}, \mathrm{S} 1}\right)$

$Q_{4, \mathrm{~S} 2}=\frac{Q_{\mathrm{S}} K_{\mathrm{A}}}{\beta}-\frac{t_{\mathrm{S} 1}}{t_{\mathrm{S} 2}} Q_{\mathrm{F}}$

where the safety margin $\beta$ is 1.03 .

The equations presented above for the determination of the flow rate in each section were obtained considering the TMB concept; therefore, in order to calculate the true flow rates in a real unit operating in SMB mode, the following equation can be applied:

$Q_{j}^{*}=Q_{j}+\frac{\varepsilon}{1-\varepsilon} Q_{s}$

where $Q_{j}^{*}$ is the flow rate in a real SMB unit.

In the present method, the determination of the operating conditions for step 2 begins by defining the value of the highest flow rate (section 1) in the system operating in SMB mode. In this work, it was considered that section 1 operates at the maximum flow rate allowable in the system $\left(Q_{1, \mathrm{~S} 2}{ }^{*}=Q_{\max }=\right.$ $\left.772.9 \mathrm{~mL} \mathrm{~min}^{-1}\right)$. By assigning this variable it is possible via combining Eqs. (21), (25), and (27) to obtain an expression for the solid velocity that will be used in the TMB-based model of step 2: in the presence of mass transfer resistances and axial dispersion is necessary.

As described above in order to determine the internal flow rates for step 2 it is necessary to choose the values of parameters $p_{\mathrm{B}}$ and $p_{\mathrm{C}}$. First of all it is necessary to determine an operation region, i.e., the range of values that can be chosen for each parameter. The relation between the parameters $p_{\mathrm{B}}$ and $p_{\mathrm{C}}$ given by Eq. (24) has to be satisfied. Graphically, each operating point $\left(p_{\mathrm{B}}, p_{\mathrm{C}}\right)$ should be above line 2 in Fig. 4 which is a graphical representation of Eq. (24). Another aspect that should be taken into account is that the value of the parameter $p_{\mathrm{C}}$ is limited by the number of columns in sections 1 and 2; therefore, the maximum value of $p_{\mathrm{C}}$ is $\left(n_{\mathrm{S} 1}+n_{\mathrm{S} 2}\right)=6$. Graphically, the maximum value of $p_{\mathrm{C}}$ is represented by line 1 in Fig. 4 .

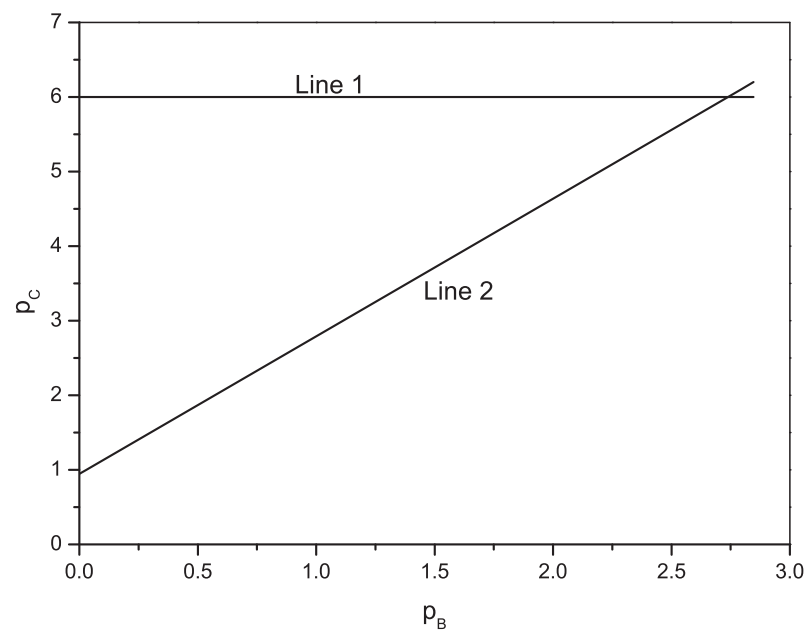

Figure 4 . JO operation region in the $p_{\mathrm{C}}$ versus $p_{\mathrm{B}}$ plot.

$Q_{s}=\frac{Q_{1, \mathrm{~S} 2}{ }^{*} \varepsilon A_{\mathrm{C}}\left[\phi_{\mathrm{C}}\left(x_{\mathrm{C} 3, \mathrm{~S} 1}+p_{\mathrm{C}} L_{\mathrm{c}}\right)-\phi_{\mathrm{B}}\left(x_{\mathrm{B} 3, \mathrm{~S} 1}+p_{\mathrm{B}} L_{\mathrm{c}}\right)\right]}{\varepsilon A_{\mathrm{C}}\left(\frac{\varepsilon}{1-\varepsilon}+\beta K_{\mathrm{C}}\right)\left[\phi_{\mathrm{C}}\left(x_{\mathrm{C} 3, \mathrm{~S} 1}+p_{\mathrm{C}} L_{\mathrm{c}}\right)-\phi_{\mathrm{B}}\left(x_{\mathrm{B} 3, \mathrm{~S} 1}+p_{\mathrm{B}} L_{\mathrm{c}}\right)\right]-t_{\mathrm{S} 1} Q_{1, \mathrm{~S} 1}\left(K_{\mathrm{C}}-K_{\mathrm{B}}\right)}$

and the corresponding switching time for the SMB model is calculated by:

$t^{*}=(1-\varepsilon) \frac{V_{\mathrm{c}}}{Q_{\mathrm{S}}}$

\section{Separation Regions}

The determination of separation regions for the SMB operation is typically performed by applying the triangle theory, where the region construction is based on the dimensionless section flow rates that guarantee the minimum purity requirements. However, in the JO process only step 2 works as an SMB, without feed stream; therefore, the triangle theory is only applicable considering average section flow rates. Moreover, the application of the triangle theory is limited to cases without mass transfer resistance and without axial dispersion. Consequently, the development of a method more adapted to the JO process
In order to evaluate the performance of the JO process for a given set of operation parameters, the purity, productivity, and solvent consumption are calculated for each outlet stream (extract, intermediate, and raffinate) according to the equations presented in Tab. 3 .

The separation regions for the JO process presented in this work were constructed by choosing the points inside the operation region given by Fig. 4 that guarantee a minimum value of purity. The procedure used to construct the separation region follows four main steps:

1) Identification of the separation problem and the characteristics of the system. One needs as inputs the adsorption isotherms, the dimension and the number of the chromatographic columns present in the system, the axial-dispersion and mass-transfer coefficients, and the maximum flow rate allowable in the system.

2) Determination of the operating conditions for step 1. Based on the separation problem and characteristics of the system, the operation conditions for step 1 can be calculated by Eqs. (16)-(19). 
Table 3. Performance criteria for the JO process.

\begin{tabular}{|c|c|c|c|}
\hline & Extract & Intermediate & Raffinate \\
\hline Purity [\%] & $\mathrm{PUX}=100 \frac{C_{\mathrm{C}, \mathrm{X}}}{C_{\mathrm{A}, \mathrm{x}}+C_{\mathrm{B}, \mathrm{X}}+C_{\mathrm{C}, \mathrm{X}}}$ & $\mathrm{PUI}=100 \frac{C_{\mathrm{B}, \mathrm{I}}}{C_{\mathrm{A}, \mathrm{I}}+C_{\mathrm{B} . \mathrm{I}}+C_{\mathrm{C}, \mathrm{I}}}$ & $\mathrm{PUR}=100 \frac{C_{\mathrm{A}, \mathrm{R}}}{C_{\mathrm{A}, \mathrm{R}}+C_{\mathrm{B}, \mathrm{R}}+C_{\mathrm{C}, \mathrm{R}}}$ \\
\hline Productivity $\left[\mathrm{g} \mathrm{h}^{-1} \mathrm{~L}^{-1}\right]$ & $\mathrm{PRX}=\frac{Q_{\mathrm{X}} C_{\mathrm{C}, \mathrm{X}}}{V_{\mathrm{T}}} \frac{t_{\mathrm{S} 2}}{t_{\mathrm{S} 1}+t_{\mathrm{S} 2}}$ & $\mathrm{PRI}=\frac{\mathrm{Q}_{\mathrm{I}} C_{\mathrm{B}, \mathrm{I}}}{V_{\mathrm{T}}} \frac{t_{\mathrm{S} 1}}{t_{\mathrm{S} 1}+t_{\mathrm{S} 2}}$ & $\mathrm{PRR}=\frac{Q_{\mathrm{R}} C_{\mathrm{A}, \mathrm{R}}}{V_{\mathrm{T}}} \frac{t_{\mathrm{S} 2}}{t_{\mathrm{S} 1}+t_{\mathrm{S} 2}}$ \\
\hline Solvent consumption $\left[\mathrm{Lg}^{-1}\right]$ & $\mathrm{SCX}=\frac{Q_{\mathrm{E}, \mathrm{S} 1} t_{\mathrm{S}_{1}}+Q_{\mathrm{E}, \mathrm{S} 2} t_{\mathrm{S} 2}}{Q_{\mathrm{X}} C_{\mathrm{C} X X} t_{\mathrm{S} 2}}$ & $\mathrm{SCI}=\frac{Q_{\mathrm{E}, \mathrm{S1}} t_{\mathrm{S1}}+Q_{\mathrm{E}, \mathrm{s} 2} t_{\mathrm{S} 2}}{Q_{\mathrm{L}} C_{\mathrm{B}, \mathrm{I}}}$ & $\mathrm{SCR}=\frac{Q_{\mathrm{E}, \mathrm{S} 1} t_{\mathrm{S} 1}+Q_{\mathrm{E}, \mathrm{S} 2} t_{\mathrm{S} 2}}{Q_{\mathrm{R}} C_{\mathrm{A}, \mathrm{R}} t_{\mathrm{S} 2}}$ \\
\hline
\end{tabular}

3) Determination of the operating region. The region where the JO operation is feasible (Fig. 4) is found based on Eq. (24) and on the dimension of the system. The operating conditions for step 2 depend on the operation point chosen.

4) Construction of the separation region. First a set of operating points $\left(p_{\mathrm{B}}, p_{\mathrm{C}}\right)$ is chosen inside the operation region. To each operating point corresponds a value of $Q_{2 / 3}$ and $t_{\mathrm{S} 2}$ given by Eqs. (21) and (22), respectively. The purity of each stream (Tab. 3) is determined by simulation of the JO process, and the operating points which present the minimum purity requirement are chosen to define the separation region.

The complete procedure used to construct the separation region is schematically illustrated in Fig. 5.

The separation region in Fig. 6 is obtained using the procedure indicated in Fig. 5 considering a minimum purity requirement of $99.9 \%$ in all outlet streams.

The separation region allows choosing an operation point based on a required purity; however, it is necessary to understand how the other performance parameters change inside the separation region, namely the productivity and the solvent consumption. This analysis can be made by fixing the value of the parameter $p_{\mathrm{B}}$ and increasing the value of $p_{\mathrm{C}}$ (Fig. 7) or by fixing the value of parameter $p_{\mathrm{C}}$ and increasing the value of $p_{\mathrm{B}}$ (Fig. 8). It can be observed by this analysis that a higher $p_{\mathrm{C}}$ inside the separation region decreases the productivity and increases the solvent consumption whereas a higher $p_{\mathrm{B}}$ has the opposite effect on both productivity and solvent consumption.

In order to better understand the variations on the JO performance inside the separation region, it is important to notice that the purity considered in each outlet stream is almost $100 \%$. Consequently, from the process mass balance results that $Q_{\mathrm{X}} C_{\mathrm{C}, \mathrm{X}} t_{\mathrm{S} 2}=Q_{\mathrm{F}} C_{\mathrm{C}, \mathrm{F}} t_{\mathrm{S} 1}, Q_{\mathrm{R}} C_{\mathrm{A}, \mathrm{R}} t_{\mathrm{S} 2}=Q_{\mathrm{F}} C_{\mathrm{A}, \mathrm{F}} t_{\mathrm{S} 1}$, and $Q_{1} C_{\mathrm{B}, 1} t_{\mathrm{S} 1}=Q_{\mathrm{F}} C_{\mathrm{B}, \mathrm{F}} t_{\mathrm{S} 1}$. Therefore, inside the considered separation region, both productivity and solvent consumption depend only on the parameter (see Tab. 3). The rise of $t_{\mathrm{S} 2}$ increases the solvent consumption and decreases the

- Choose a set of operating points $\left(p_{B}, p_{C}\right)$ inside the operation region; - Determine the operating condition for each operating point with $\mathrm{Eq}(23-$ 31);

- Simulate the JO operation for each point:

- Calculate the purity in each stream;

- Choose the operating points that give the minimum purity requirement to construct the separation region;

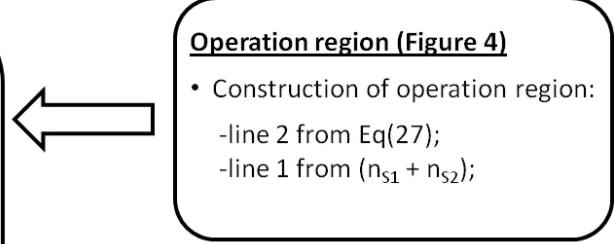

Figure 5. Flow chart of the procedure used to determine the separation region. productivity. Therefore, it is important to understand the variation of $t_{\mathrm{S} 2}$ inside the separation region.

Analyzing Eqs. (21) and (28), it can be concluded that the variation of $t_{\mathrm{S} 2}$ with $p_{\mathrm{B}}$ and $p_{\mathrm{B}}$ is directly proportional to the following function:

$$
\begin{aligned}
f\left(\phi_{\mathrm{B}}, \phi_{\mathrm{C}}\right)= & \phi_{\mathrm{C}}\left(x_{\mathrm{C} 3, \mathrm{~S} 1}+p_{\mathrm{C}} L_{\mathrm{c}}\right) \\
& -\phi_{\mathrm{B}}\left(x_{\mathrm{B} 3, \mathrm{~S} 1}+p_{\mathrm{B}} L_{\mathrm{c}}\right)
\end{aligned}
$$

Operating conditions for Step 1

- Feed Flow-rate from Eq(22);

The function derivatives are:

$\frac{\partial f\left(\phi_{\mathrm{B}}, \phi_{\mathrm{C}}\right)}{\partial p_{\mathrm{B}}}=-\phi_{\mathrm{B}} L_{\mathrm{c}}$
$\frac{\partial f\left(\phi_{\mathrm{B}}, \phi_{\mathrm{C}}\right)}{\partial p_{\mathrm{C}}}=\phi_{\mathrm{C}} L_{\mathrm{c}}$

The analysis of $f\left(\phi_{\mathrm{B}}, \phi_{\mathrm{C}}\right)$ shows that $t_{\mathrm{S} 2}$ decreases with a positive variation of $p_{\mathrm{B}}$ and with a negative variation of $p_{\mathrm{C}}$. It can be also concluded that since $\phi_{\mathrm{C}}>\phi_{\mathrm{B}}$, the effect of $p_{\mathrm{C}}$ on $t_{\mathrm{S} 2}$ is high- 


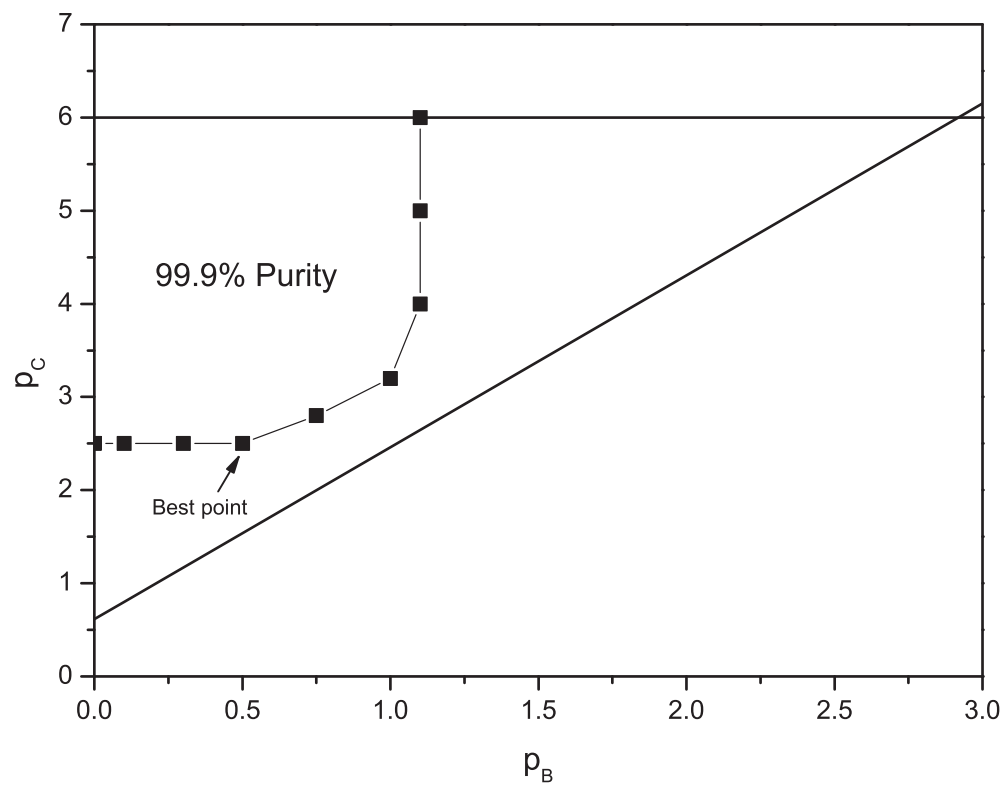

Figure 6. JO separation region for $99.9 \%$ of purity.

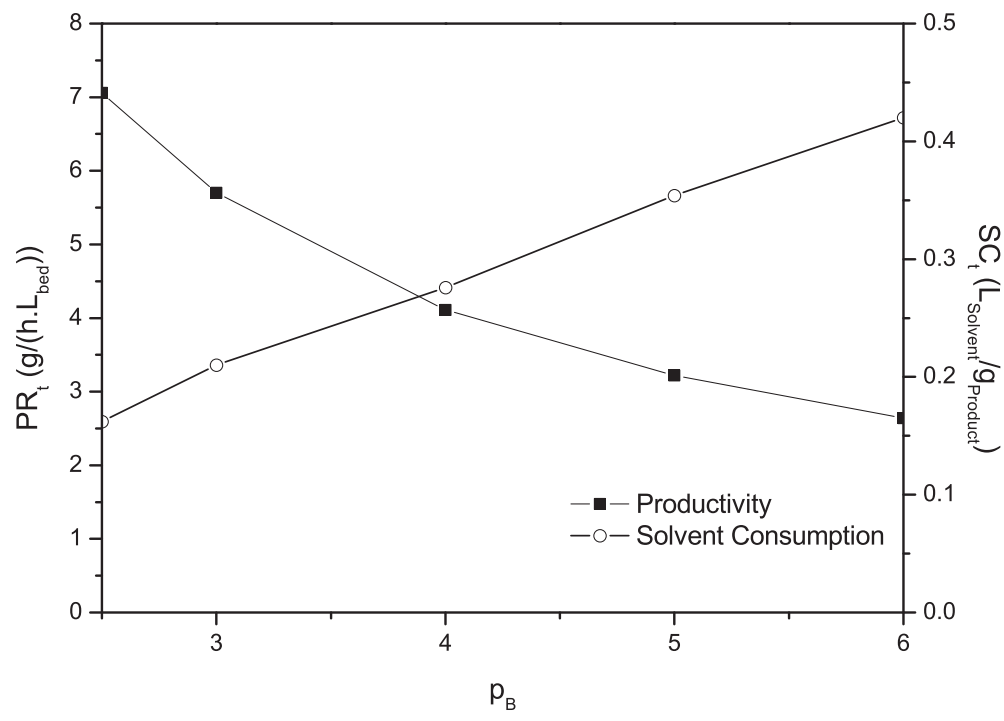

Figure 7. Variation of productivity and solvent consumption with $p_{\mathrm{C}}$ for a fixed value of $p_{\mathrm{B}}=0.5$.

er than the effect of $p_{\mathrm{B}}$. Therefore, since inside the separation region the higher variation allowable is for the parameter $p_{C}$, the best operation point will be the maximum $p_{\mathrm{B}}$ possible fixing the minimum $p_{\mathrm{C}}$ (see Fig. 6).

The performance of JO at the best operation point is displayed in Tab. 4 which corresponds to the operation conditions presented in Tab. 5.

The performance of the JO process can be compared with that of two SMBs in series. The comparison was made assuming:

1) The constant feed flow rate of the first SMB was considered to be equal to $Q_{F} \frac{t_{\mathrm{s} 1}}{t_{\mathrm{s} 1}+t_{\mathrm{s} 2}}$ since in the JO system the feed enters in the process during the time $t_{\mathrm{S} 1}$ and a complete cycle has the duration of $t_{\mathrm{S} 1}+t_{\mathrm{S} 2}$. The feed flow rate of the second SMB is equal to the extract flow rate of the first SMB.

2) The total amount of adsorbent of the JO system was equally divided by the two SMBs.

3) The operation conditions of both SMBs were determined considering the equilibrium theory. The operating conditions are summarized in Tab. 6.

Tab. 7 provides the performance data of the twoSMB system for the separation of the ternary mixture. The comparison between the performances of the JO system (Tab. 4) with the two-SMB system (Tab. 7) indicates similar results. However, the investment in two SMBs is always higher than in one JO system.

Besides the operation parameters, the study of the influence of the system properties is also important. Fig. 9 demonstrates the influence of the mass transfer coefficient, $k_{\mathrm{p}}$, in the separation region. The results show that the size of the separation region is reduced when the mass transfer resistance is higher.

The impact of mass transfer resistance on the internal concentration profile of component B is illustrated in Fig. 10. The decrease of $k_{\mathrm{p}}$ enlarges the width of the concentration peak due to the increase of the dispersive effects. This effect limits the range positions allowable by the concentration peaks without causing the contamination of outlet streams. Consequently, the separation regions are smaller for high mass transfer resistances (see Fig. 9).

Another feature which can be perceived from Fig. 9 is the overlapping of the separations regions for $k_{\mathrm{p}}=0.5 \mathrm{~s}^{-1}$ and $k_{\mathrm{p}}=1 \mathrm{~s}^{-1}$ when $p_{\mathrm{C}}=3$ and $p_{\mathrm{C}}=4$. This can be explained by two aspects. First, the operation points where the concentration front of the component $\mathrm{C}$ travels between $p_{\mathrm{C}}=3$ and $p_{\mathrm{C}}=4$ correspond to high concentrations of component $\mathrm{C}$ in the extract stream. Consequently, any small contamination caused by the concentration front of component $\mathrm{B}$ has low impact on the extract stream purity, therefore, high values of $p_{\mathrm{B}}$ are possible. The second aspect is that the dispersive effect caused by decreasing $k_{\mathrm{p}}=1 \mathrm{~s}^{-1}$ to $k_{\mathrm{p}}=0.5 \mathrm{~s}^{-1}$ is relatively small (Fig. 10), and at high concentrations of component $\mathrm{C}$ in the extract stream the possible contamination caused by the spreading of the concentration front of component $\mathrm{B}$ has a minor influence on the extract purity.

Table 4. Performance of the JO process at $p_{\mathrm{B}}=0.5$ and $p_{\mathrm{C}}=2.5$.

\begin{tabular}{lc}
\hline & Outlet streams \\
\hline Purity [\%] & 100 \\
Productivity $\left[\mathrm{g} \mathrm{h}^{-1} \mathrm{~L}^{-1}\right]$ & 2.35 \\
Solvent consumption $\left[\mathrm{Lg}^{-1}\right]$ & 0.05 \\
\hline
\end{tabular}




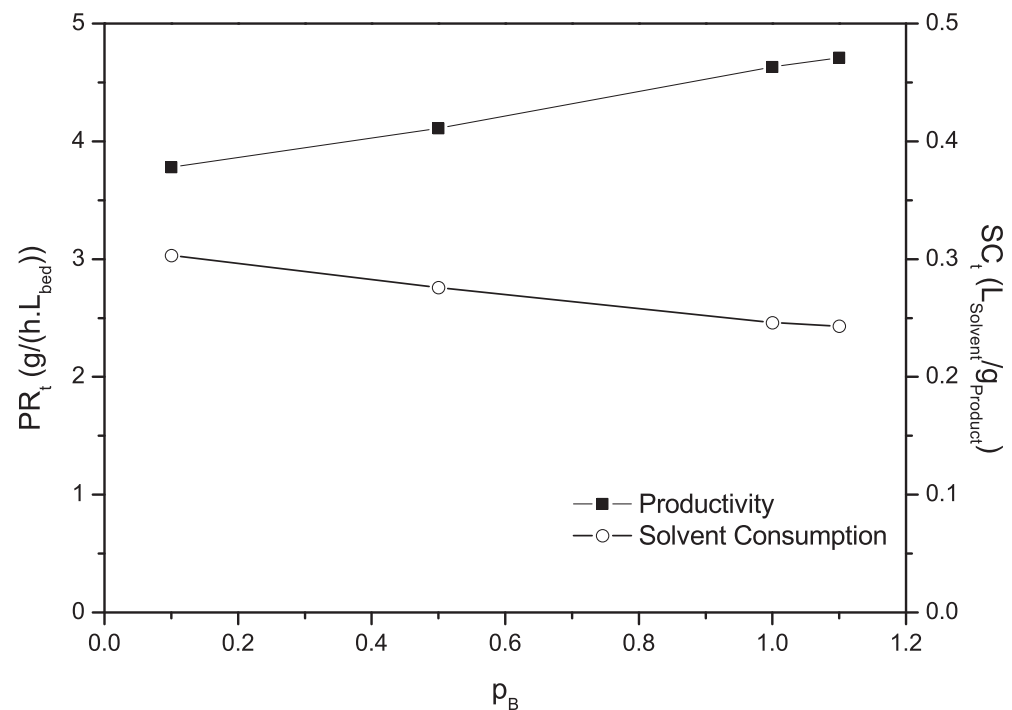

Figure 8. Variation of productivity and solvent consumption with $p_{\mathrm{B}}$ for a fixed value of $p_{\mathrm{C}}=4$.

Table 5. Operation conditions of the JO process for both SMB and $\mathrm{TMB}$ models at $p_{\mathrm{B}}=0.5$ and $p_{\mathrm{C}}=2.5$.

\begin{tabular}{|c|c|c|}
\hline \\
\hline$t_{\mathrm{S} 1}[\mathrm{~min}]$ & 18.17 & \\
\hline$Q_{\mathrm{E}, \mathrm{S} 1}\left[\mathrm{~mL} \min ^{-1}\right]$ & 422.9 & \\
\hline$Q_{\mathrm{F}}\left[\mathrm{mL} \min ^{-1}\right]$ & 350.0 & \\
\hline Step 2 & SMB & $\mathrm{TMB}$ \\
\hline$t_{\mathrm{S} 2}[\mathrm{~min}]$ & 103.9 & \\
\hline$t^{\star}[\mathrm{min}]$ & 9.8 & - \\
\hline$Q_{1, \mathrm{~S} 2}\left[\mathrm{~mL} \min ^{-1}\right]$ & 772.9 & 319.9 \\
\hline$Q_{2 / 3, \mathrm{~S} 2}\left[\mathrm{~mL} \min ^{-1}\right]$ & 623.1 & 170.1 \\
\hline$Q_{4, \mathrm{~S} 2}\left[\mathrm{~mL} \min ^{-1}\right]$ & 517.2 & 64.2 \\
\hline$Q_{\mathrm{S}}\left[\mathrm{mL} \mathrm{min}^{-1}\right]$ & - & 679.6 \\
\hline$Q_{\mathrm{X}}\left[\mathrm{mL} \min ^{-1}\right]$ & 149.8 & \\
\hline$Q_{R}\left[\mathrm{~mL} \mathrm{~min}{ }^{-1}\right]$ & 105.9 & \\
\hline$Q_{\mathrm{E}, \mathrm{S} 2}\left[\mathrm{~mL} \min ^{-1}\right]$ & 255.7 & \\
\hline
\end{tabular}

\section{Conclusions}

A mathematical model of the JO process for the ternary separation is presented. Step 1 of the process is modeled as a series of fixed-bed columns and step 2 as a TMB without the feed stream.

A new methodology for establishing the operating conditions is described which allows the determination of a separation region, defined by the operating points that provide a minimum purity requirement. Therefore, the range of operability of the process becomes well-defined. The influence of change of operation points on the performance parameters inside the operation region is studied.

Analysis of the influence of mass transfer resistance demonstrates that this parameter affects size and shape of the separation region; therefore, for systems with high mass transfer resistances, the construction of the separation region becomes a useful tool in order to define the optimum operation conditions. Moreover, the investigation of the shape of the separation regions showed that the dispersive effects in the column play an important role for its construction and consequently for the determination of the operation conditions.

\section{Acknowledgment}

Financial support by the Portuguese R\&D foundation FCT (Fundação para a Ciência e a Tecnologia) and the European Community through FEDER (project PTDC/EQU-EQU/119025/2010) is gratefully acknowledged. This work was cofinanced by FCT/MEC and FEDER under Program PT2020 (Project UID/ EQU/50020/2013).

The authors have declared no conflict of interest.

Table 6. Operating conditions fot the two SMBs system.

\begin{tabular}{lll}
\hline & SMB1 & SMB2 \\
\hline Feed & $Q_{\mathrm{F}}=52.01 \mathrm{~mL} \mathrm{~min}^{-1}$ & $Q_{\mathrm{F}}=124.90 \mathrm{~mL} \mathrm{~min}^{-1}$ \\
& $C_{\mathrm{A}, 0}=100 \mathrm{~g} \mathrm{~L}^{-1}$ & $C_{\mathrm{B}, 0}=41.71 \mathrm{~g} \mathrm{~L}^{-1}$ \\
& $C_{\mathrm{B}, 0}=100 \mathrm{~g} \mathrm{~L}^{-1}$ & $C_{\mathrm{C}, 0}=41.71 \mathrm{~g} \mathrm{~L}^{-1}$ \\
& $C_{\mathrm{C}, 0}=100 \mathrm{~g} \mathrm{~L}^{-1}$ & \\
Raffinate & $Q_{\mathrm{R}}=53.54 \mathrm{~mL} \mathrm{~min}^{-1}$ & $Q_{\mathrm{R}}=130.40 \mathrm{~mL} \mathrm{~min}^{-1}$ \\
& $C_{\mathrm{A}, \mathrm{R}}=97.31 \mathrm{~g} \mathrm{~L}^{-1}$ & $C_{\mathrm{B}, \mathrm{R}}=39.96 \mathrm{~g} \mathrm{~L}^{-1}$ \\
Extract & $Q_{\mathrm{X}}=124.90 \mathrm{~mL} \mathrm{~min}^{-1}$ & $Q_{\mathrm{X}}=134.27 \mathrm{~mL} \mathrm{~min}^{-1}$ \\
& $C_{\mathrm{B}, \mathrm{X}}=41.71 \mathrm{~g} \mathrm{~L}^{-1}$ & $C_{\mathrm{C}, \mathrm{X}}=38.80 \mathrm{~g} \mathrm{~L}^{-1}$ \\
& $C_{\mathrm{C}, \mathrm{X}}=41.71 \mathrm{~g} \mathrm{~L}^{-1}$ & \\
Eluent & $Q_{\mathrm{EL}}=126.34 \mathrm{~mL} \mathrm{~min}^{-1}$ & $Q_{\mathrm{EL}}=139.73 \mathrm{~mL} \mathrm{~min}^{-1}$ \\
Switching time & $t^{*}=12.8 \mathrm{~min}$ & $t^{*}=6.9 \mathrm{~min}$ \\
\hline
\end{tabular}

Table 7. Performance of the two SMBs system.

\begin{tabular}{lc}
\hline & Outlet streams \\
\hline Purity [\%] & 100 \\
Productivity $\left[\mathrm{g} \mathrm{h}^{-1} \mathrm{~L}^{-1}\right]$ & 2.352 \\
Solvent consumption $\left[\mathrm{Lg}^{-1}\right]$ & 0.051 \\
\hline
\end{tabular}




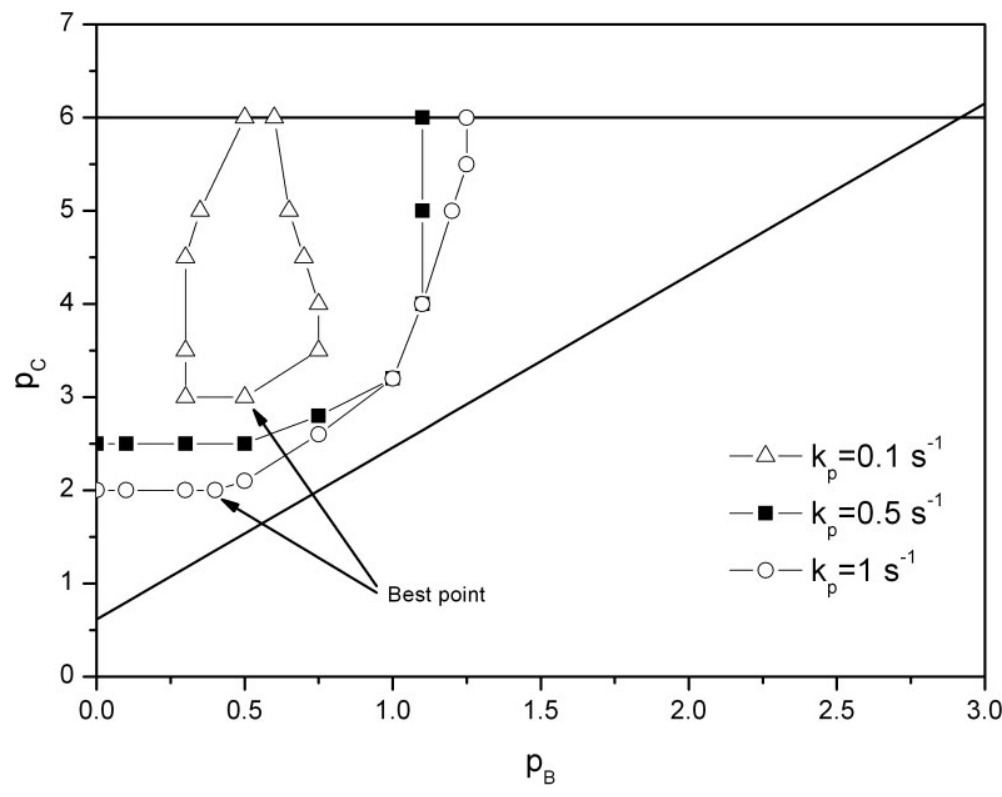

Figure 9. Influence of the mass transfer coefficient in the separation region (99.9\%)

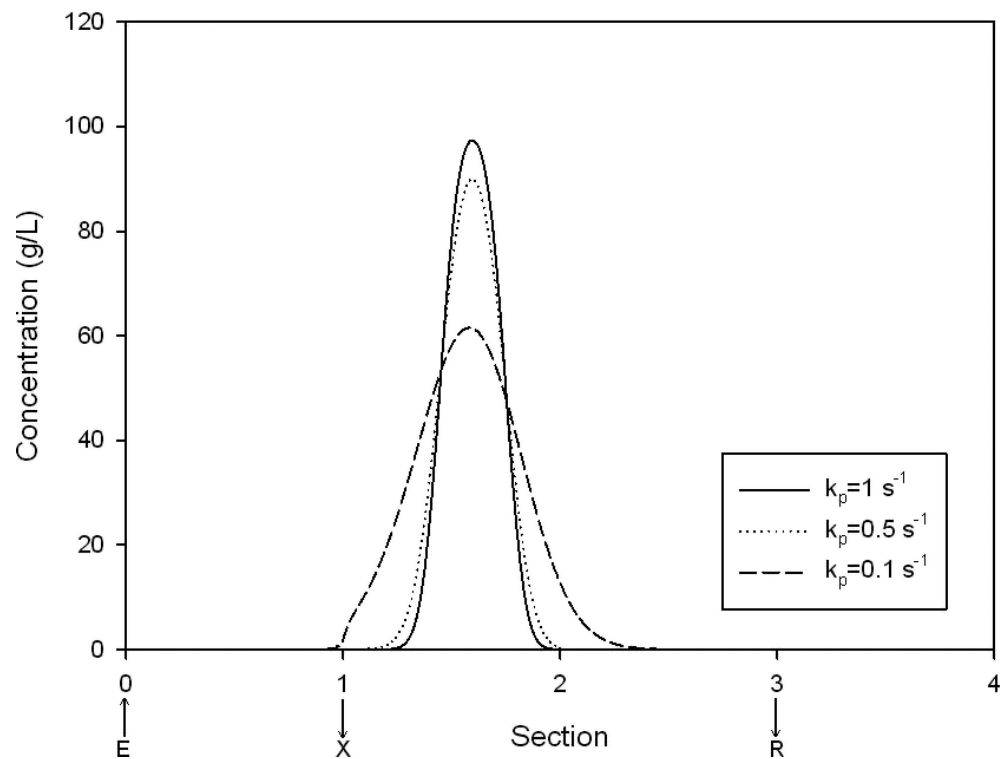

Figure 10. Internal concentration profile of component $B$ at the end of step 2 $\left(p_{\mathrm{C}}=2.5\right.$ and $\left.p_{\mathrm{B}}=0.5\right)$. The inlet and outlet streams are represented by: (E) eluent; $(X)$ extract; $(\mathrm{R})$ raffinate.

\section{Appendix A}

The duration of step $1, t_{\mathrm{S} 1}$, is assumed to be the time required for the intermediate component to travel from the feed to a certain position of section 3. $t_{\mathrm{S} 1}$ is obtained from the expressions proposed by Haynes and Sharma [36] for the first and second moments of the pulse response of a packed bed considering the dispersed plug-flow model, macropore and micropore diffusion, external film resistance, and linear isotherm.
The retention time of the intermediate component (B) is given by the first moment, $\mu_{1}$ :

$\bar{t}_{\mathrm{B}}=\tau\left[1+\frac{(1-\varepsilon)}{\varepsilon} K_{\mathrm{B}}\right]$

and the variance is obtained from the second central moment, $\mu_{2}-\mu_{1}^{2}$ :

$\frac{\sigma^{2}}{2 \bar{t}_{\mathrm{B}}^{2}}=\frac{1}{P e}+\left(\frac{\varepsilon}{1-\varepsilon}\right) \frac{1}{k_{\mathrm{p}} \tau K_{\mathrm{B}}}\left(1+\frac{\varepsilon}{(1-\varepsilon) K_{\mathrm{B}}}\right)^{-2}$

Substituting (A.1) in (A.2), the expression for the standard deviation is achieved:

$\sigma=\sqrt{\frac{2 \bar{t}_{\mathrm{B}}^{2}}{P e}+\frac{2}{k_{p}}\left(\bar{t}_{\mathrm{B}}-\tau\right)}$

In order to ensure that the concentration front of component $\mathrm{B}$ travels to the position $p_{t \mathrm{~S} 1}$ in section 3 and in order to guarantee that no component $\mathrm{B}$ is present after that position, within an assumed error of less than $5 \%$, the duration of step 1 is given by:

$t_{\mathrm{S} 1}=\bar{t}_{\mathrm{B}}-2 \sigma=\bar{t}_{\mathrm{B}}-2 \sqrt{\frac{2 \bar{t}_{\mathrm{B}}^{2}}{P e}+\frac{2}{k_{\mathrm{p}}}\left(\bar{t}_{\mathrm{B}}-\tau\right)}$

Eq. (A.4) can be rewritten as follows:

$t_{\mathrm{S} 1}=\bar{t}_{\mathrm{B}}\left[1-2 \sqrt{\frac{2}{P e}+\frac{2}{k_{\mathrm{p}} \bar{t}_{\mathrm{B}}}\left(\frac{\phi_{\mathrm{B}}-1}{\phi_{\mathrm{B}}}\right)}\right]$

where

$\phi_{\mathrm{B}}=1+\frac{1-\varepsilon}{\varepsilon} K_{\mathrm{B}}$

The calculation of the internal flow rates for step 2 is based on the following assumptions:

- Component A (less retained component) moves $\left(p_{\mathrm{A}} L_{\mathrm{C}}-x_{\mathrm{A}, 3, \mathrm{~S} 1}\right)$ with the liquid phase in order to be collected in the raffinate.

- Component B (intermediate component) moves $\left(x_{\mathrm{B}, 3, \mathrm{~S} 1}+p_{\mathrm{B}} L_{\mathrm{C}}\right)$ with the solid phase in order to stay inside section 2 .

- Component C (more retained component) moves $\left(x_{\mathrm{C}, 3, \mathrm{~S} 1}+p_{\mathrm{C}} L_{\mathrm{C}}\right)$ with the solid phase in order to be collected in the extract.

The distance traveled by each component $i$ in section $j$ during step 1 is defined by:

$$
x_{i j, \mathrm{~S} 1}=\frac{t_{\mathrm{S} 1} Q_{j}}{\varepsilon A_{\mathrm{c}}\left(1+\frac{1-\varepsilon}{\varepsilon} K_{i}\right)}
$$

and the distance traveled by each component $i$ in section $j$ during step 2 is given by:

$x_{i j, \mathrm{~S} 2}=\frac{t_{\mathrm{S} 2}\left(Q_{j}-Q_{\mathrm{S}} K_{i}\right)}{\varepsilon A_{\mathrm{c}}\left(1+\frac{1-\varepsilon}{\varepsilon} K_{i}\right)}$ 
The above assumptions can be mathematically expressed by the following equations:

$$
\begin{aligned}
x_{\mathrm{A}, 2 / 3, \mathrm{~S} 2} & =p_{\mathrm{A}} L_{\mathrm{c}}-x_{\mathrm{A} 3, \mathrm{~S} 1} \\
& =\frac{t_{\mathrm{S} 2}}{\varepsilon A_{\mathrm{c}} \phi_{\mathrm{A}}}\left(Q_{2 / 3, \mathrm{~S} 2}-Q_{\mathrm{S}} K_{\mathrm{A}}\right) \quad\left(p_{\mathrm{A}} \geq \frac{x_{\mathrm{A} 3, \mathrm{~S} 1}}{L_{\mathrm{C}}}\right) \\
x_{\mathrm{B}, 2 / 3, \mathrm{~S} 2} & =-\left(x_{\mathrm{B} 3, \mathrm{~S} 1}+p_{\mathrm{B}} L_{\mathrm{C}}\right) \\
& =\frac{t_{\mathrm{S} 2}}{\varepsilon A_{\mathrm{c}} \phi_{\mathrm{B}}}\left(Q_{2 / 3, \mathrm{~S} 2}-Q_{\mathrm{S}} K_{\mathrm{B}}\right) \quad\left(0<p_{\mathrm{B}}<n_{\mathrm{S} 2}\right) \\
x_{\mathrm{C}, 2 / 3, \mathrm{~S} 2} & =-\left(x_{\mathrm{C} 3, \mathrm{~S} 1}+p_{\mathrm{C}} L_{\mathrm{C}}\right) \\
& =\frac{t_{\mathrm{S} 2}}{\varepsilon A_{\mathrm{c}} \phi_{\mathrm{C}}}\left(Q_{2} 2,3, \mathrm{~S} 2-Q_{\mathrm{S}} K_{\mathrm{C}}\right) \quad\left(p_{\mathrm{C}}>0\right)
\end{aligned}
$$

where

$\phi_{i}=1+\frac{1-\varepsilon}{\varepsilon} K_{i}$

Looking at the adsorption parameters presented in Tab. 1, it can be concluded that in this case the harder separation is between the components $\mathrm{B}$ and $\mathrm{C}$, since the selectivity factors are $\alpha_{\mathrm{AB}}=K_{\mathrm{B}} / K_{\mathrm{A}}=2.1$ and $\alpha_{\mathrm{BC}}=K_{\mathrm{C}} / K_{\mathrm{B}}=1.7$. Therefore, a procedure similar to the Strategy 1 proposed by Borges da Silva et al. $[32,33]$, for cases where the harder separation is between the intermediate and the strongly adsorbed component, was followed and Eqs. (A.10) and (A.11) were used to determine the liquid flow rate in section 2 and 3 during step 2. However, it is worth noting that the expression for $Q_{2 / 3}$ obtained is different from Borges da Silva et al. since, in the present work, the solid flow rate is initially fixed and an expression for $t_{\mathrm{S} 2}$ is found instead of one for $Q_{S}$ :

$Q_{2 / 3, \mathrm{~S} 2}=\left(\frac{\phi_{\mathrm{B}} K_{\mathrm{C}} x_{\mathrm{B}, 2 / 3, \mathrm{~S} 2}-\phi_{\mathrm{C}} K_{\mathrm{B}} x_{\mathrm{C}, 2 / 3, \mathrm{~S} 2}}{\phi_{\mathrm{B}} x_{\mathrm{B}, 2 / 3, \mathrm{~S} 2}-\phi_{\mathrm{C}} x_{\mathrm{C}, 2 / 3, \mathrm{~S} 2}}\right) Q_{s}$

Substituting Eq. (A.13) in Eq. (A.11) provides the duration of step 2:

$t_{\mathrm{S} 2}=\frac{\varepsilon A}{Q_{\mathrm{S}}\left(K_{\mathrm{C}}-K_{\mathrm{B}}\right)}\left(\phi_{\mathrm{B}} x_{\mathrm{B}, 2 / 3, \mathrm{~S} 2}-\phi_{\mathrm{C}} x_{\mathrm{C}, 2 / 3, \mathrm{~S} 2}\right)$

In order to satisfy the constraint associated with Eq. (A.9) $\left(p_{\mathrm{A}} \geq \frac{x_{\mathrm{A}, 3, \mathrm{~S} 1}}{L_{\mathrm{C}}}\right)$, the following inequality should be verified:

$Q_{2 / 3, S 2} \geq Q_{\mathrm{S}} K_{\mathrm{A}}$

\begin{tabular}{|c|c|c|}
\hline$A_{\mathrm{c}}$ & {$\left[\mathrm{dm}^{2}\right]$} & column section area \\
\hline$C$ & {$\left[\mathrm{gL}^{-1}\right]$} & concentration of liquid phase \\
\hline$D_{L}$ & {$\left[\mathrm{dm}^{2} \min ^{-1}\right]$} & axial dispersion coefficient \\
\hline s & {$[-]$} & function of $\phi_{\mathrm{B}}$ and $\phi_{\mathrm{C}}$ \\
\hline$k_{p}$ & {$\left[\min ^{-1}\right]$} & intraparticle mass transfer coefficient \\
\hline$L_{\mathrm{c}}$ & {$[\mathrm{dm}]$} & SMB column length \\
\hline$L_{j}$ & {$[\mathrm{dm}]$} & SMB section length \\
\hline$n_{\mathrm{S}}$ & {$[-]$} & number of columns in an SMB section \\
\hline$p_{\mathrm{A}}$ & {$[-]$} & $\begin{array}{l}\text { dimensionless distance of component } \\
\text { A during step } 2\end{array}$ \\
\hline$p_{\mathrm{B}}$ & {$[-]$} & $\begin{array}{l}\text { dimensionless distance of component } B \\
\text { during step } 2\end{array}$ \\
\hline$p_{\mathrm{C}}$ & {$[-]$} & $\begin{array}{l}\text { dimensionless distance of component } \\
\mathrm{C} \text { during step } 2\end{array}$ \\
\hline $\mathrm{Pe}$ & {$[-]$} & Péclet number \\
\hline$p_{Q S 1}$ & {$[-]$} & $\begin{array}{l}\text { dimensionless distance of component } B \\
\text { in section } 2 \text { during step } 1\end{array}$ \\
\hline$P R_{i}$ & {$\left[\mathrm{gh}^{-1} \mathrm{~L}^{-1}\right]$} & productivity \\
\hline$p_{t S 1}$ & {$[-]$} & $\begin{array}{l}\text { dimensionless distance of component } B \\
\text { in section } 3 \text { during step } 1\end{array}$ \\
\hline$P U_{i}$ & {$[\%]$} & purity \\
\hline$q$ & {$\left[\mathrm{~g} \mathrm{~L}^{-1}\right]$} & adsorbed phase concentration \\
\hline$Q$ & {$\left[\mathrm{~L} \mathrm{~min}^{-1}\right]$} & liquid phase flow rate \\
\hline$Q_{2 / 3, \mathrm{~S} 2}$ & {$\left[\mathrm{~L} \mathrm{~min}^{-1}\right]$} & $\begin{array}{l}\text { liquid phase flow rate in sections } 2 \text { and } \\
3 \text { during step } 2\end{array}$ \\
\hline$q^{*}$ & {$\left[\mathrm{~g} \mathrm{~L}^{-1}\right]$} & $\begin{array}{l}\text { adsorbed phase equilibrium } \\
\text { concentration }\end{array}$ \\
\hline$Q_{s}$ & {$\left[\mathrm{~L} \mathrm{~min}^{-1}\right]$} & solid-phase flow rate \\
\hline$S C_{i}$ & {$\left[\mathrm{Lg}^{-1}\right]$} & solvent consumption \\
\hline$t$ & {$[\mathrm{~min}]$} & time variable \\
\hline$t^{*}$ & {$[\mathrm{~min}]$} & switching time \\
\hline$u_{\mathrm{s}}$ & {$\left[\mathrm{dm} \mathrm{min} \min ^{-1}\right]$} & solid-phase velocity \\
\hline$V_{\mathrm{c}}$ & {$\left[\mathrm{dm}^{3}\right]$} & column volume \\
\hline$x_{i j, \mathrm{~S} 1}$ & {$[\mathrm{dm}]$} & $\begin{array}{l}\text { distance traveled by component } i \\
\text { inside section } j \text { during step } 1\end{array}$ \\
\hline$x_{i j, \mathrm{~S} 2}$ & {$[\mathrm{dm}]$} & $\begin{array}{l}\text { distance traveled by component } i \\
\text { inside section } j \text { during step } 2\end{array}$ \\
\hline$x$ & & dimensionless space variable \\
\hline & {$[\mathrm{dm}]$} & space variable \\
\hline
\end{tabular}

Substituting Eq. (A.13) in Eq. (A.15) and combining with Eqs. (A.9)-(A.12) results in:

\begin{tabular}{|c|c|c|}
\hline$\alpha$ & {$[-]$} & number of mass transfer units \\
\hline$\beta$ & {$[-]$} & safety margin \\
\hline$\gamma$ & {$[-]$} & $\begin{array}{l}\text { ratio of fluid and solid interstitial } \\
\text { velocities }\end{array}$ \\
\hline$\varepsilon$ & {$[-]$} & bed porosity \\
\hline$\theta$ & {$[-]$} & dimensionless time variable \\
\hline$v$ & {$[\mathrm{dm} \mathrm{min}-1]$} & liquid-phase interstitial velocity \\
\hline$\tau$ & {$[\mathrm{min}]$} & space time \\
\hline
\end{tabular}

$p_{\mathrm{B}} \leq \frac{\phi_{\mathrm{C}}}{\phi_{\mathrm{B}}}\left(\frac{x_{\mathrm{C}, 3, \mathrm{~S} 1}}{L_{\mathrm{C}}}+p_{\mathrm{C}}\right)\left(\frac{K_{\mathrm{B}}-K_{\mathrm{A}}}{K_{\mathrm{C}}-K_{\mathrm{A}}}\right)-\frac{x_{\mathrm{C}, 3, \mathrm{~S} 1}}{L_{\mathrm{C}}}$

\section{Symbols used}

\section{Greek letters}

\section{Subscripts}

$\begin{array}{ll}\text { A } & \text { less retained component } \\ \text { B } & \text { intermediate retained component } \\ \text { C } & \text { more retained component }\end{array}$


E eluent

F feed

I intermediate

$i \quad$ relative to a component

$j \quad$ relative to an $\mathrm{SMB}$ section

$k$ relative to a cycle

$\mathrm{R}$ raffinate

S1 step1

S2 step 2

$\mathrm{X}$ extract

\section{References}

[1] D. B. Broughton, C. G. Gerhold, U.S. Patent 2,985,589, 1961.

[2] D. C. S. Azevedo, A. E. Rodrigues, AIChE J. 2001, 47, 2042-2051.

[3] L. S. Pais, J. M. Loureiro, A. E. Rodrigues, Chem. Eng. Sci. 1997, 52, 245-257.

[4] J. Strube, U. Altenhöner, M. Meurer, H. Schmidt-Traub, M. Schulte, J. Chromatogr. A 1997, 769, 81-92.

[5] M. J. Gattuso, B. McCulloch, D. W. House, W. M. Baumann, K. Gottschall, Chimica Oggi 1996, 14, X1-20.

[6] J. Wu, Q. Peng, W. Arlt, M. Minceva, J. Chromatogr. A 2009, 1216, 8793-8805.

[7] P. E. Barker, G. Ganetsos, J. Ajongwen, A. Akintoye, Chem. Eng. J. 1992, 50, B23-B28.

[8] Z. Zhang, M. Mazzotti, M. Morbidelli, J. Chromatogr. A 2003, 1006, 87-99.

[9] Y. Kawajiri, L. T. Biegler, AIChE J. 2006, 52, 1343-1350.

[10] H. Schramm, A. Kienle, M. Kaspereit, A. Seidel-Morgenstern, Chem. Eng. Sci. 2003, 58, 5217-5227.

[11] O. Ludemann-Hombourger, R. M. Nicoud, M. Bailly, Sep. Sci. Technol. 2000, 35, 1829-1862.

[12] L. C. Keßler, A. Seidel-Morgenstern, J. Chromatogr. A 2008, 1207, 55-71.

[13] P. S. Gomes, A. E. Rodrigues, Sep. Sci. Technol. 2010, 45, 2259-2272.

[14] K. M. Kim, C. H. Lee, J. Chromatogr. A 2013, 1311, 79-89.
[15] J. Bentley, Y. Kawajiri, AIChE J. 2013, 59, 736-746.

[16] J. G. Palacios, M. Kaspereit, A. Kienle, Chem. Eng. Technol. 2011, 34, 688-698.

[17] C. S. M. Pereira, M. Zabka, V. M. T. M. Silva, A. E. Rodrigues, Chem. Eng. Sci. 2009, 64, 3301-3310.

[18] V. M. T. M. Silva, A. E. Rodrigues, AIChE J. 2005, 51, 2752-2768.

[19] N. S. Graça, L. S. Pais, V. M. T. M. Silva, A. E. Rodrigues, Chem. Eng. Process. 2011, 50, 1214-1225.

[20] L. S. Pais, A. E. Rodrigues, J. Chromatogr. A 2003, 1006, 33-44.

[21] P. C. Wankatt, Ind. Eng. Chem. Res. 2001, 40, 6185-6193.

[22] S. H. Jin, P. C. Wankat, Ind. Eng. Chem. Res. 2005, 44, 1906-1913.

[23] A. Navarro, H. Caruel, L. Rigal, P. Phemius, J. Chromatogr. A 1997, 770, 39-50.

[24] X. Wang, C. B. Ching, Chem. Eng. Sci. 2005, 60, 1337-1347.

[25] S. Katsuo, M. Mazzotti, J. Chromatogr. A 2010, 1217, 1354-1361.

[26] S. Jermann, S. Katsuo, M. Mazzotti, Org. Process Res. Dev. 2012, 16, 311-322.

[27] M. Ando, M. Tanimura, M. Tamura, U.S. Patent No. 4,970,002, 1990.

[28] T. Massuda, T. Sonobe, F. Matsuda, U.S. Patent No. 5,198,120, 1993

[29] J. Nowak, D. Antos, A. Seidel-Morgenstern, J. Chromatogr. A 2012, 1253, 58-70.

[30] G. Agrawal, B. Sreedhar, Y. Kawajiri, J. Chromatogr. A 2014, 1356, 82-95.

[31] V. G. Mata, A. E. Rodrigues, J. Chromatogr. A 2001, 939, 23-40.

[32] E. A. Borges Da Silva, A. E. Rodrigues, AIChE J. 2006, 52, 3794-3812.

[33] E. A. B. Da Silva, A. E. Rodrigues, Sep. Sci. Technol. 2008, 43, 533-566.

[34] L. Wiåniewski, C. S. M. Pereira, M. Polakovič, A. E. Rodrigues, Adsorption 2014, 20, 483-492.

[35] M. C. Rabelo, C. S. M. Pereira, S. Rodrigues, A. E. Rodrigues, D. C. S. Azevedo, Adsorpt. Sci. Technol. 2012, 30, 773-784.

[36] H. W. Haynes, P. N. Sarma, AIChE J. 1973, 19, 1043-1046. 